\title{
Survey of Brucella infection and malaria among Abattoir workers in Kampala and Mbarara Districts, Uganda
}

\author{
Immaculate Nabukenya ${ }^{1 *}$, Deogratius Kaddu-Mulindwa ${ }^{2+}$ and George William Nasinyama ${ }^{1,3+}$
}

\begin{abstract}
Background: Brucellosis is among the most widespread zoonotic infections estimated at $14 \%$ in Uganda. A cross-sectional study was conducted to estimate the sero-prevalence, risk factors of Brucella infection and malaria among abattoir workers.

Methods: A survey was conducted among 232 abattoir workers in main abattoirs of Kampala and Mbarara districts in February 2007. A pre-tested questionnaire captured socio-demographic and occupational data. Brachial vein blood was tested for Brucella using Microplate Agglutination Test (MAT) and Standard Tube Agglutination Test (STAT) with a cut off titre of 1:160, and giemsa stained blood slides for malaria. Data was analyzed in SPSS 17.0.

Results: Seven males (3\%, $\mathrm{n}=232)$ had malaria and dual brucella and Plasmodium falciparum malaria was found in one person. Brucella sero-positivity was $10 \%(95 \% \mathrm{Cl} 6-16 ; n=232)$ with $12 \%(n=161)$ in Kampala and $7 \%(n=71)$ in Mbarara district. Non-use of protective gear Odds ratio (OR 3.3, 95\% Cl (1.25 - 50) and working in the abattoir beyond 5 years OR $2.495 \% \mathrm{Cl}(1.4-5.6)$ were associated with increased risk of Brucella infection. Age, sex, religion, keeping animals and consumption of raw milk or products were not significant.

Conclusions: Brucella infection is a real risk among abattoir workers and use of full protective gear reduced risk significantly. Sensitization and public health care programs are needed to control this emerging problem.
\end{abstract}

Keywords: Brucella, Malaria, Brucellosis, Abattoir workers, Zoonoses, MAT, STAT, Seropositivity

\section{Background}

Brucellosis is among the most widespread zoonotic infections causing human suffering and economic losses in livestock [1-3]. However, it is often a neglected cause of morbidity in many regions of the world [3,4]. The disease is most common in rural areas among those involved in animal husbandry, meat-packers, dairy workers, veterinarians, consumers of unprocessed dairy products and in urban livestock keeping populations [2,5]. Brucella infection is transmitted from animals (cattle, goats, pigs, sheep, camels and buffaloes) to humans by bacteria belonging to the genus Brucella. B. abortus, B. suis, and

\footnotetext{
* Correspondence: lennfaith@yahoo.com

${ }^{\dagger}$ Equal contributors

'Department of Biosecurity, Ecosystems and Veterinary Public Health, College of Veterinary Medicine, Animal Resources and Biosecurity, Makerere University, Kampala, Uganda

Full list of author information is available at the end of the article
}

B. melitensis are the causative agents, which affect cattle, swine, goats and sheep respectively are most pathogenic to humans [1]. B. canis and marine species also have zoonotic potential but are not as pathogenic.

The global burden of human brucellosis remains enormous with more than 500,000 infections per year worldwide [4-6]. Brucellosis has been reported in the Middle East [7], Mediterranean region [5], Northern and Sub-Saharan countries in Africa $[4,6,8]$ with prevalence of $5-55 \%$ in humans and $8-46 \%$ in animals [9]. For example, in central Greece, prevalence was 32.49 cases/100,000 inhabitants [5]. In Iran, a Brucellosis endemic country, a study on brucellosis and HIV co-infection found a very high prevalence of $73 \%$ among HIV positive patients compared to $24 \%$ in HIV negative patients indicating a statistical difference in infection rates [7]. Among hospital patients in Markudi Nigeria, overall brucellosis prevalence was $7.6 \%$, and $43.8 \%$

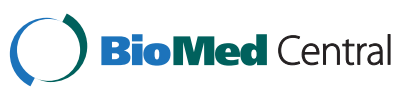


of these were abattoir workers and butchers [10]. Over $55 \%$ of 7161 people examined in different parts of Western Nigeria have positive Brucella abortus antibodies in their sera. Higher incidences of titres were found among dairy farmers and slaughter men than in the general population. The rates of infection among human and cattle populations in two farms studied were very similar [10]. In Egypt, incidence ranges from 0.28 to 70 per 100,000 population $[4,11]$ and $11 \%$ prevalence among hospital patients [12].

Brucellosis is a highly prevalent disease in Uganda with $7-42.2 \%[2,13,14]$ among cattle and goats, posing a big threat to abattoir workers and consumers. A study done among hospital patients estimated 18-24\% brucellosis prevalence [15] while it was estimated at $6-7 \%$ among herdsmen and consumers of raw milk and products [14]. In Kampala, Uganda, of 150 patients with joint pain, general malaise, and/or constant headache, $73 \%$ were found to be suffering from malaria and $13.3 \%$ from brucellosis showing a scenario often leading to misdiagnosis [16].

Few recent studies in Africa and globally have considered the abattoir workers as an occupational high risk group. A study among high risk groups in Erzurum, Turkey found higher infection among abattoir workers [1]. In India, assessment of 165 serum samples of abattoir associated personnel with dot-ELISA found $25.5 \%, 40 \%$ and $11 \%$ positive for brucellosis, listeriosis and tuberculosis respectively [17]. In Pakistan, Mukhtar and Kokab found 21.7\% prevalence using ELISA with job category, age and duration in the abattoir as significant risk factors [18].

Diagnosis of brucellosis based on the clinical picture alone is difficult due to similarity with clinical presentations of other infections [3,9]. Symptoms and signs are non-specific and several other febrile illnesses, for example glandular fever, influenza, malaria and enteric infections may be simulated $[11,18,19]$. When an unusual complication is present, it may be overlooked [12]. Therefore, laboratory testing is an absolute prerequisite for proper diagnosis through blood culture and isolation of the causative organisms or serological testing [12]. However, culture requires special media, takes several weeks of incubation and has low sensitivity. Serological tests including the serum agglutination test (SAT or STAT), anti-human globulin test (Coombs test), complement fixation test (CFT) and Enzyme-linked Immunosorbent Assay (ELISA), therefore, are indispensable for an accurate diagnosis [9].

Malaria is endemic in Uganda with prevalence as high as $70 \%$ in patients with pyrexia of unknown origin [16]. Few studies have focused on brucellosis prevalence in Africa $[4,6]$ and misdiagnosis with common conditions such as malaria and typhoid remains a challenge. In Uganda, brucellosis prevalence and the occupation link is unknown to health workers, and malaria, a common tropical disease which sometimes clinically mimics brucellosis has not been widely studied in apparently healthy populations $[12,16]$. There is no published data on prevalence of brucellosis in Uganda among abattoir workers which is a high risk group and the study therefore sought to address this gap. At the same time, this study assessed the prevalence of malaria in this apparently healthy population.

\section{Methods}

\section{Study area}

The study was carried out in Kampala City Council abattoir (KCCA) in Kampala district and Mbarara Municipal Council abattoir (MCA) in Mbarara district. KCCA handles a big slaughter load from many parts of the country. MCA is located in the cattle corridor, with high cattle production, thus representing significant risk to the abattoir workers.

\section{Study design, participant enrolment and laboratory processing}

The survey carried out among 232 apparently healthy abattoir workers in January to February 2007 used quantitative data collection methods. The sample size was calculated based on $95 \%$ confidence level and prevalence of $18 \%$ [20]. Adult men and women who had worked for at least three months in the abattoirs and consented to participate were selected, with a proportion of $87 \%$ and $92 \%$ of the workers in KCCA and MCA respectively enrolled into the study.

To identify risk factors, socio-demographic variables like age, sex, education level and religion were measured. In addition, occupational factors such as use of protective gear, animal species handled and work done in the abattoir, duration of exposure; health-related factors (malaria, malaria-like symptoms and previous use of antibiotics) were studied as the independent variables using a questionnaire. Brachial vein blood was used to make a thick blood smear which was giemsa stained to assess for malaria parasitaemia. Serological screening by Microplate Agglutination test (MAT) and confirmation by Standard Tube Agglutination Test (STAT) [21] using B. abortus antigens from Veterinary Laboratory Agency UK, was done in Mulago Hospital Microbiology laboratory. Samples with any agglutination by MAT were further processed by STAT to quantify the amount of agglutination and a titer of 1:160 or greater indicated seropositivity.

\section{Statistical analysis}

Data was entered in Epidata 3.0, cleaned, exported and analyzed in Statistical Package for Social Scientists, SPSS version 17.0 (Apache software, 2007). Descriptive statistics to summarize the data as well as odds ratios and the 95\% confidence intervals were computed. For risk factor analysis, stepwise backward logistic regression was used to fit the best model after assessing and controlling for interaction and confounding. After bivariable analysis, 
factors with less than $\mathrm{p}<0.2$ (Table 1 ) were included in the multivariable analysis.

\section{Ethical issues}

Ethical approval to conduct the study was received from Makerere University Clinical Epidemiology Unit, Faculty of Medicine Research and Ethics Committee, administrators of KCCA and Mbarara Municipal Council abattoirs. Written consent was obtained from the participants. Participants with Brucella infection were referred to appropriate health facilities for treatment.

\section{Results}

A total of 232 people who work in Kampala City Council abattoir, KCCA (161) and Mbarara Municipal Council abattoir, MCA (71) abattoirs were interviewed and tested for Brucella infection and malaria.

\section{Socio-demographics}

The majority of the workers were males $(78 \%, \mathrm{n}=232)$ and overall mean age was $32.7+/-9$ years (range 19-70 and median 30 years). Up to $91 \%$ of the workers had some education and $48 \%$ had at least attained secondary school education. The religion to which majority of the participants were affiliated was Islam $(50 \%, \mathrm{n}=232)$ and $69 \%$ were married (Table 2). By occupation category in the abattoir, slaughterers of cattle, goats and sheep were $35 \%$, followed by $19 \%$ who prepare food, meat traders $(15 \%)$ and transporters (11\%).

Only 7 people $(3 \%, \mathrm{n}=232)$, all males aged $25-35$ years had Plasmodium falciparum malaria. In addition, there was a dual occurrence of Brucella infection and malaria due to Plasmodium falciparum in one person. The overall prevalence of Brucella infection was 10\% (95\% CI 6 - 16; $\mathrm{n}=232$ ). On gender desegregation, the prevalence of Brucella infection in females was $12 \%(\mathrm{n}=52)$ and $10 \%$ $(\mathrm{n}=180)$ in males. The proportion of participants with Brucella infection among participants with at least secondary education and Muslims was each 13\%. Kampala district had more Brucella seropositive abattoir workers $(12 \%, \mathrm{n}=161)$ compared to Mbarara district $(7 \%, \mathrm{n}=71)$, though not significantly different $(\mathrm{p}=0.08)$. Ninety percent $(n=24)$ of the workers who reported positive diagnosis and treatment for brucellosis in the past two years were still positive. The prevalence established in workers who consumed raw milk or products and those who do not was similar ( $10 \%$ and $11 \%$ respectively). A summary of the results is in Table 2 .

\section{Knowledge and past experience with brucellosis}

The majority of the participants, $61 \%(\mathrm{n}=232)$ reportedly had heard of brucellosis and of these only 30\% $(n=142)$ said they knew how the disease was transmitted. The most commonly cited modes of brucellosis transmission were ingestion of meat that is not well prepared and drinking raw milk (55\%, $\mathrm{n}=42$ and $38 \%$ respectively). Past experience with brucellosis was reported by $11 \%(n=232)$ while $23 \%(\mathrm{n}=232)$ reported that they knew someone who had suffered from brucellosis (Table 2). Undulant fever and joint pains were the most common symptoms reported $67 \%$ and $60 \%$ respectively $(n=67)$ as shown in Table 3.

\section{Risk factors}

The majority of the participants reported using some protective gear when working $(92 \%, \mathrm{n}=232)$ but only $5 \%(\mathrm{n}=214)$ had full protective gear. Seroprevalence of Brucella infection was up to $11 \%(\mathrm{n}=214)$ among abattoir workers without full protective gear. When asked how often they used the protective gear, 95\%, $(n=214)$ reported routine use, twice or more times a week by $4 \%$ and once a week by $0.9 \%$.

Only $35 \%(\mathrm{n}=232)$ of the participants consumed raw milk or its products, with $7 \%$ brucellosis seropositivity in this proportion. Of the 81 participants who drank raw milk and/or unprocessed products, $41 \%$ drank raw milk while $17 \%$ ate uncooked cow ghee. Results showed that only $27 \%(\mathrm{n}=232)$ kept animals at home, of whom $28 \%$ $(n=61)$ kept goats; $25 \%$ had cattle; $15 \%$ kept dogs and

Table 1 Significant characteristics with Brucella infection at bivariable analysis

\begin{tabular}{|c|c|c|c|c|}
\hline Variable & & Frequency (/n) & Unadjusted OR (95\% Cl) & $\mathrm{p}$ value \\
\hline \multirow[t]{2}{*}{ Age } & 30 yrs or less & $10 / 118$ & 1 & 0.097 \\
\hline & Above 30 yrs & $14 / 114$ & $1.2(0.9-1.6)$ & \\
\hline \multirow[t]{2}{*}{ Protective gear } & Full gear & $1 / 11$ & 1 & 0.05 \\
\hline & Not full gear & $23 / 221$ & $2.5(1.1-22.0)$ & \\
\hline \multirow[t]{2}{*}{ Duration in abattoir } & 4 yrs \& less & $4 / 53$ & 1 & 0.12 \\
\hline & Above 5 yrs & $20 / 179$ & $1.2(1.1-1.4)$ & \\
\hline \multirow[t]{2}{*}{ Keep animals } & No & $7 / 169$ & 1 & 0.14 \\
\hline & Yes & $17 / 63$ & $1.3(0.9-1.9)$ & \\
\hline \multirow[t]{2}{*}{ District with abattoir } & Mbarara & $5 / 71$ & 1 & 0.13 \\
\hline & Kampala & $19 / 161$ & $1.2(1.0-1.4)$ & \\
\hline
\end{tabular}


Table 2 Seroprevalence of Brucella infection among abattoir workers in Kampala and Mbarara districts in different strata $(n=232)$

\begin{tabular}{|c|c|c|c|c|}
\hline Variable & & $(n=232, \%)$ & +ve Kampala $(161, \%)$ & +ve Mbarara $(71, \%)$ \\
\hline Overall & & $24(10)$ & $19(12)$ & $5(7)$ \\
\hline \multirow[t]{2}{*}{ Sex } & Male & $18(8)$ & $13(8)$ & $5(7)$ \\
\hline & Female & $6(3)$ & $6(4)$ & $0(0)$ \\
\hline \multirow[t]{5}{*}{ Age } & 20 and below & $1(1)$ & $1(1)$ & $0(0)$ \\
\hline & $21-30$ & $6(4)$ & $6(4)$ & $3(3)$ \\
\hline & $31-40$ & $8(5)$ & $8(5)$ & $0(0)$ \\
\hline & $41-50$ & $3(2)$ & $3(2)$ & $2(3)$ \\
\hline & Above 50 & $1(1)$ & $1(1)$ & $0(0)$ \\
\hline \multirow[t]{4}{*}{ Education } & None & $3(1)$ & $2(1)$ & $1(1)$ \\
\hline & Primary & $7(3)$ & $5(3)$ & $2(3)$ \\
\hline & Secondary & $13(6)$ & $12(8)$ & $1(1)$ \\
\hline & Tertiary & $1(1)$ & $0(0)$ & $1(1)$ \\
\hline \multirow[t]{5}{*}{ Religion } & Catholic & 7 (3) & $5(3)$ & $2(3)$ \\
\hline & Protestant & $4(2)$ & $3(2)$ & $1(1)$ \\
\hline & Muslim & $13(6)$ & $11(7)$ & $2(3)$ \\
\hline & Born again & $0(0)$ & $0(0)$ & $0(0)$ \\
\hline & SDA & $0(0)$ & $0(0)$ & $0(0)$ \\
\hline Marital & Single & $6(3)$ & $4(3)$ & $2(3)$ \\
\hline \multirow[t]{3}{*}{ status } & Married & $17(7)$ & $14(9)$ & $3(4)$ \\
\hline & Separated & $1(1)$ & $1(1)$ & $0(0)$ \\
\hline & Divorced & & $0(0)$ & $0(0)$ \\
\hline Keep & No & $8(3)$ & $2(1)$ & $4(6)$ \\
\hline animals & Yes & $16(7)$ & $17(11)$ & $1(1)$ \\
\hline Malaria & No & $23(10)$ & $2(1)$ & $0(0)$ \\
\hline in past 3 & Yes & $1(1)$ & $17(7)$ & $5(7)$ \\
\hline \multicolumn{5}{|l|}{ Months } \\
\hline Raw milk & No & $8(3)$ & $6(4)$ & $2(3)$ \\
\hline \multirow[t]{2}{*}{ /products } & Yes & $16(7)$ & $13(8)$ & $3(4)$ \\
\hline & No & $21(9)$ & $18(11)$ & $5(7)$ \\
\hline Protective gear & Yes & $3(2)$ & $1(1)$ & $0(0)$ \\
\hline Brucellosis & No & $6(3)$ & $3(2)$ & $3(4)$ \\
\hline (past 2 years) & Yes & $18(8)$ & $16(10)$ & $2(3)$ \\
\hline
\end{tabular}

cats. Interaction of the workers with these animals was during grazing or feeding.

Use of full protective gear; odds ratio, OR 0.3 (95\% CI $0.02-0.8)$ and duration of more than five years in the abattoir, OR 2.4 (95\% CI 1.4 - 5.6) were associated with reduced and high risk for infection respectively. The final model predicting Brucella seropositivity is presented in Table 4.

\section{Discussion}

The low prevalence of malaria (3\%) is possibly because this was a healthy population and the blood used was from the brachial vein rather than the finger tip at the periphery where more parasites sequestrate. Information on whether the malaria positives workers had taken malaria pills over the last few days prior to commencement of this study was not collected. This would provide a plausible explanation to the low prevalence. However, Maichomo and others reported 9\% prevalence of malaria and 13\% brucellosis in 488 patients with flu-like illnesses and higher prevalence is reported in patients rather than healthy populations [22]. The overall seroprevalence of Brucella infection in this study was high, with one in every ten abattoir workers seropositive. This prevalence parallels 
Table 3 Reported symptoms of brucellosis previously experienced by abattoir workers or patients they knew had suffered from brucellosis $(n=67)$

\begin{tabular}{lll}
\hline Symptom & Frequency & Percentage \\
\hline Undulant fever & 45 & 67 \\
Joint pains & 40 & 60 \\
Back pain & 31 & 46 \\
Headaches & 23 & 34 \\
Weakness & 23 & 34 \\
Fatigue & 14 & 21 \\
Abdominal pain & 11 & 16 \\
Chills & 11 & 16 \\
Excessive sweating & 9 & 13 \\
Loss of appetite & 8 & 12 \\
Night sweats & 7 & 10
\end{tabular}

that in animals $(8-46 \%)$ which are the primary source for the abattoir workers [2]. Similar studies among abattoir workers elsewhere have found similar results $[1,18,23]$. Dual occurrence of malaria and brucellosis has been reported before in a traveler from Chad to Europe [19]. There were similar levels of exposure among abattoir workers and herdsmen who deal with animals from different areas of brucellosis endemicity.

Since brucellosis indirectly causes infertility through abortion, this is a reason for sale of such animals. In addition, $10 \%$ (24) of the participants attested to having been diagnosed and treated for brucellosis before. Since the study was a serosurvey, the tests used did not discriminate between current active and past infections. The reactive proportion therefore was still part of the overall prevalence obtained. What is strange is that despite the high prevalence of Brucella infection in humans, it is not considered for routine laboratory referrals in cases of acute febrile illness. The low prevalence of malaria may indicate the need to consider brucellosis in the high risk populations presenting with febrile illnesses.

Table 4 Final model predicting Brucella seropositivity among abattoir workers

\begin{tabular}{llll}
\hline Variable & Coefficient & OR $(\mathbf{9 5 \%} \mathbf{C l})$ & p-value \\
\hline Keep animals & 2.4 & $1.1(0.3-4.2)$ & 0.190 \\
No protective gear & 1.26 & $3.3(1.25-50)$ & $0.02^{* *}$ \\
District & 0.22 & $2.1(0.8-5.4)$ & 0.135 \\
Duration of exposure & 1.54 & $2.4(1.4-5.6)$ & $0.04^{* *}$ \\
Age & 2.60 & $1.1(0.03-10.4)$ & 0.13 \\
Constant & 8.3 & & 0.105 \\
\hline
\end{tabular}

**Significant predictors of Brucella seropositivity at $\mathrm{p}<0.05$.
The proportion of individuals who had full protective gear (gloves, white coat/overall, gumboots and or no head gear) and were Brucella seropositive was small (9\%) compared to that without (23\%). Also those without full protective gear were about three times as likely to be Brucella seropositive as those with full protective gear. However, 9\% seroprevalence among those with full gear may be explained by inhalation as the mode of transmission [23].

Socio-demographic factors (age, sex, education level, religion) were all not significantly associated with Brucella infection unlike in other studies [1]. Although significantly higher prevalence was noted in males than females in a brucellosis and HIV co-infection study [7], another study found no association between brucellosis and sex or age although females were more affected than males and those with age in the second and fourth deciles were more affected [10]. This latter and our findings do not concur with other studies which found age and gender associated significantly $[8,24]$. Other factors like duration of exposure and type of work done in the abattoir were also not statistically significant, although $57 \%$ had worked in the abattoir for six to 15 years.

This study being a cross sectional one had no temporal background and was not able to establish the causal relationship between brucellosis and possible factors associated. Owing to the fact that assessment of the factors was through self report by the participants responses to a questionnaire, there was a potential bias due to underreporting. Measurement bias was reduced by the two tests which improved on the specificity and included less false positives. No factor was found to cause interaction or confounding.

\section{Conclusion}

The seroprevalence of Brucella infection is high, suggesting that one in ten abattoir workers is infected. In order to reduce Brucella infection, abattoir workers need to use full protective gear. Sensitization of abattoir workers, management and the general population about brucellosis will help in effective control and prevention.

\section{Abbreviations \\ KCC: Kampala City Council; STAT: Standard tube agglutination test; \\ MCA: Mbarara Municipal Council Abattoir; MAT: Microplate agglutination test.}

\section{Competing interests}

The authors declare that they have no competing interests.

\section{Authors' contributions}

$\mathrm{NI}, \mathrm{KMD}$ and NGW were involved in design of the study as well as in manuscript write up. KMD and NGW supervised the field and laboratory work. NI participated in data analysis and write up. KMD is a microbiologist, majorly bacteriology with a veterinary background. As a Professor, he has supervised many students with several research grants in this area. Currently focusing on Enterobacteriaceae, he continues to inspire many through research, teaching and grant management. NGW has conducted a lot of research in the area of zoonoses including brucellosis and tuberculosis in urban and peri-urban settings of Uganda. He has supported many students 
and junior researchers in areas of epidemiology, public health and preventive veterinary medicine. All authors read and approved the final manuscript.

\section{Acknowledgements}

We would like to thank the management, staff of the study sites and the abattoir workers who were extremely cooperative and helpful during data collection. Dr. Kamya Moses and Dr. Tamara of Uganda Malaria Surveillance Project and the technicians in Microbiology laboratory of Mulago Hospital are highly recognized. Professor Karamagi Charles, Mrs. Joan Kalyango and other members of the Clinical Epidemiology Unit of Makerere University are thanked. Last but not least, we would like to extend our sincere appreciation to Belgian Technical Cooperation (BTC) for funding the study.

\section{Author details}

${ }^{1}$ Department of Biosecurity, Ecosystems and Veterinary Public Health, College of Veterinary Medicine, Animal Resources and Biosecurity, Makerere University, Kampala, Uganda. '2Department of Medical Microbiology, School of Biomedical Sciences, College of Health Sciences, Makerere University, P.O. Box 7072, Kampala, Uganda. ${ }^{3}$ Directorate of Research and Graduate Training, Makerere University, Kampala, Uganda.

Received: 19 February 2013 Accepted: 24 September 2013 Published: 30 September 2013

\section{References}

1. Ayyildiz A: Survey of brucellosis seroprevalence in risk groups in Erzurum, Turkey. Prague / Czech Republic: 14th European Congress of Clinical Microbiology and Infectious Diseases; 2004.

2. Nakavuma JKS, Opuda-Asibo J: Serostudy of Brucella abortus in cattle and goat in central and southern Uganda. Uganda J Agric SC 1999, 4:13-18.

3. WHO: Zoonoses and Food Safety, in World Health Organization. Geneva, Switzerland; 2006.

4. Dean AS, et al: Global Burden of Human Brucellosis: A Systematic Review of Disease Frequency. PLoS Negl Trop Dis 2012, 6(10):e1865.

5. Markos M, et al: Epidemiological and Clinical Aspects of Human Brucellosis in Central Greece. J Infect Dis 2007, 60(6):362-366.

6. Pappas $\mathrm{G}$, et al: The new global map of human brucellosis. Lancet Infect Dis 2006, 6:91-99.

7. Abdollahi A, et al: Brucellosis serology in HIV-infected patients. Int J Infect Dis 2010, 14(10):e904-e906.

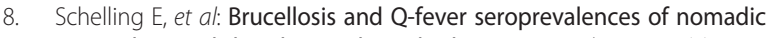
pastoralists and their livestock in Chad. Prev Vet Med 2003, 61(4):279-293.

9. Henk LS, Cutler SJ: Contributions of biotechnology to the control and prevention of brucellosis in Africa. Afr J Biotechnol 2004, 3(12):631-636.

10. Ofukwu AR, Yohanna CA, Abuh HA: Brucella infection among hospital patients in Makurdi, North central Nigeria. Niger J Parasitol 2006, 16:73-78.

11. Jennings $G J$, et al: Brucellosis as a cause of acute febrile illness in Egypt. Trans R Soc Trop Med Hyg 2007, 101:707-713.

12. Afifi $S$, et al: Hospital-based surveillance for acute febrile illness in Egypt: a focus on community-acquired bloodstream infections. Am J Trop Med Hyg 2005, 73(2):392-399.

13. Bernard F, et al: Tuberculosis and brucellosis prevalence survey on dairy cattle in Mbarara milk basin. Uganda Prev Vet Med J 2005, 67(4):267-281.

14. Ssekawojjwa E: Risk factors for brucellosis seroprevalence in cattle, goats and human beings in Uganda. Kampala: MSc Thesis Makerere Univesity; 2006.

15. Ndyabahinduka DG, Chu IH: Brucellosis in Uganda. Int J Zoonoses 1984, 11:59-64.

16. Mutanda LN: Selected laboratory tests in febrile patients in Kampala Uganda. East Afr Med J 1998, 75(2):68-72.

17. Barbuddhe SB, et al: Seropositivity for intracellular bacterial infections among abattoir associated personnels. J Commun Dis 2000, 32(4):255-259.

18. Mukhtar F, Kokab F: Brucella serology in abattoir workers. J Ayub Med Coll Abbottabad 2008, 20(3):57-61.

19. Badiaga S, et al: Imported Brucellosis associated with Plasmodium falciparum malaria in a traveler returning from the tropics. J Travel Med 2005, 12(5):282-284.

20. Martin SW, Meek AH, Willeberg P: Veterinary Epidemiology; Principles and methods. Ames, lowa: lowa State University Press; 1987.

21. Lucero NE, Bolpe JE: The buffered plate antigen as a screening test for Human Brucellosis. J Clin Micrbiol 1998, 36:1425-1427.
22. Maichomo M, et al: Study of brucellosis in a pastoral community and evaluation of the usefulness of clinical signs and symptoms in differentiating it from other flu-like diseases. Afr J Health Sci 2000, 7(3-4):114-119.

23. Kaufmann AF, et al: Airborne spread of brucellosis. Ann N Y Acad Sci 2006 353:105-114.

24. John K, et al: Quantifying Risk Factors for Human Brucellosis in Rura Northern Tanzania. PLoS One 2010, 5(4):e9968.

doi:10.1186/1471-2458-13-901

Cite this article as: Nabukenya et al: Survey of Brucella infection and malaria among Abattoir workers in Kampala and Mbarara Districts, Uganda. BMC Public Health 2013 13:901.

\section{Submit your next manuscript to BioMed Central and take full advantage of:}

- Convenient online submission

- Thorough peer review

- No space constraints or color figure charges

- Immediate publication on acceptance

- Inclusion in PubMed, CAS, Scopus and Google Scholar

- Research which is freely available for redistribution

Submit your manuscript at www.biomedcentral.com/submit
C) Biomed Central 